\title{
NOUVELLES CERTAINES DES ISLES DU PERU (LYON 1534) \\ Edición, traducción y notas ${ }^{\mathrm{I}}$
}

\author{
KURT BALDINGER \\ Universidad de Heidelberg \\ José Luis Rivarola \\ Pontificia Universidad Católica del Perú
}

\begin{abstract}
El texto que editamos aqui - cinco siglos después del descubrimiento de América- constituye el primer testimonio francés del descubrimiento del Perú por Francisco Pizarro en 1533. Sin edición moderna, el texto se conocía por una reproducción fotográfica de la princeps que el historiador peruano Raúl Porras Barrenechea incluyó en Las Relaciones Primitivas de la Conquista del Perú ${ }^{2}$ en 1937 y por una "traducción aproximada" del mismo Porras Barrenechea ${ }^{3}$. En Francia, el folleto no parece haberse conservado, a pesar de haber sido impreso por François Juste, el impresor de Rabelais, en Lyon, el mismo año que Gargantua. En efecto, no hemos logrado encontrar ni un solo ejemplar de esta edición en Francia, ni en la Biblioteca Nacional ni en ninguna otra. Falta inclusive $-\mathrm{y}$ le agradecemos a Colette Demaizière esta verificación- en el fondo especial dedicado a las ediciones de François Juste en Lyon mismo. El único ejemplar conocido es el que se encuentra en la North Library del British Museum (G. 6492-1-3): es el ejemplar que manejó Porras Barrenechea y que ahora sirve de base a nuestra edición a través de la fotocopia proporcionada por dicha biblioteca.
\end{abstract}

1 La edición del texto, con el comentario concerniente al léxico francés -que no cabe en el presente marco-, se publica simultáneamente en la Revue de Linguistique Romane, 56, 1992.

2 Cuadernos de Historia del Perú, núm. 2, serie: Los cronistas de la conquista, I), publicado en París (Imprimeries Les Presses Modernes-Palais Royal).

3 Ib., págs. 69-78. 
La atención que nos mereció este texto se sitúa en el marco de nuestro interés filológico y lingüístico en las crónicas peruanas, concretado hasta hoy en los estudios sobre la tercera parte de la Crónica del Perú de Pedro de Cieza de León ${ }^{4}$ y sobre la Relación del descubrimiento y conquista del Perú de Pedro Pizarro ${ }^{5}$. Al revisar el texto de las Nouvelles comprobamos que la traducción de Porras Barrenechea es, en efecto, "aproximada" y contiene graves errores. Mencionemos solamente tres: la traducción "medias finas de oro" (¿las indias vistiendo tales prendas?) se basa en una lectura equivocada de bassins d'or "recipientes de oro" como bas fins d'or; la traducción "un rosario sobre el cual se ponen los platos sobre la mesa" reposa en una interpretación equivocada de chapelet $^{7}$, que, en una acepción técnica, se refiere a una especie de soporte para platos, acepción que no tiene el esp. rosario; y el caso más grave, sin duda, es el que le hace suponer, a partir de una mala lectura de tentes como têtes, "la indole sanguinaria de Atahualpa inútilmente contradicha por biógrafos insolventes del monarca quiteño" 8 .

Más difícil es reconocer los errores del refundidor francés, quien, ciertamente, se equivocaba también al leer sus fuentes españolas, como en el caso de su traducción de un item del inventario de las riquezas llevadas a Europa : "Item deux lictz de maíz et y a en chascune (sic) deux mazor[qu] es d'or", donde lictz "lechos, camas", que no da sentido, es ciertamente una mala lectura de cannas, quizá escrito con abreviatura (mod. cañas), interpretado como camas (cf. la nota 24 de nuestra traducción).

Pero Porras Barrenechea tuvo el mérito de haber hecho conocer este rarísimo texto "de valor histórico excepcional, además de bibliográfico" ?. Se trata, sin duda, de la traducción de una fuente española, desgraciada-

- Kurt Baldinger, «Pedro Cieza de León, Descubrimiento y Conquista del Perú: el descubrimiento del manuscrito original y su importancia para la historia del léxico español», Philologica Hispaniensia. In honorem Manuel Alvar, Madrid, Gredos, 1983, I, págs. 103-117 (en versión alemana ZRPh 99, 1983, págs. 367-377); «Vocabulario de Cieza de León», Lexis, VII, 1, págs. 1-137, luego incluido en la edición limeña de la tercera parte de la Crónica del Perú de Cieza, prólogo y notas de F. Cantù, Lima (Pontificia Universidad Católica del Perú), 1987. De la primera, la segunda y la cuarta parte (parcialmente) hay ediciones recientes en Lima (Pontificia Universidad Católica del Perú, 1984, 1985 y 1991, respectivamente); los dos primeros volúmenes han sido reseñados por K. B. en la ZRPh 102, 1986, págs. 697 y sig. Sobre la ed. madrileña de 1984, modernizada y sin valor lingülstico, cf. K. B., ZRPh 102, 1986, págs. 698 y sig.

- José Luis Rivarola, «Las versiones de la Relación del descubrimiento y conquista de los Reinos del Perú, de Pedro Pizarro. Estudio crítico-textual, Lexis VII, 1983, págs. 159-185; id., «Para la historia de los americanismos léxicos. A propósito de una nueva versión de la Relación de Pedro Pizarro», Filología, XX, 1985, págs. 69-87.

- Op. cit., pág. 13.

7 Op. cit., pág. 14.

8 Op. cit., pág. 72 ; vid. la nota 12 de nuestra traducción.

- Op. cit., pág. 34. 
mente perdida, lo cual aumenta el valor documental de aquélla ${ }^{10}$. Y el detallado estudio del historiador peruano ${ }^{11}$ nos compensa un poco de los errores en la interpretación de nuestra obrilla. Ella no es la única relación que apareció en 1534 fuera de España: se conoce un texto italiano y otro alemán. El texto francés corresponde al texto italiano, sin ser una traducción de éste ${ }^{12}$. Porras Barrenechea aporta pruebas y da argumentos válidos de que el o los textos españoles de base fueron escritos en Panamá, adonde llegaban todas las noticias del Perú; asimismo, da buenas razones acerca de que eran altos funcionarios de este 'cuartel general' los que redactaban estas pequeñas crónicas o relaciones para enviarlas a Europa, al rey de España, especialmente el licenciado Gaspar de Espinoza y el licenciado Antonio de la Gama. Uno de estos documentos, el de Espinoza, fechado el 21 de julio de 1533 y dirigido al rey, es particularmente interesante, porque el texto italiano de 1534 lo traduce casi literalmente y el texto alemán también lo toma como base; en cuanto al texto italiano, "la identidad entre los dos documentos es absoluta. El editor italiano no agrega nada"; "La [versión] alemana parece sintetizar el texto primitivo español" "13. Que el texto de base del texto francés proviene del medio panameño es, por lo menos, probable. $\mathrm{Y}$ el final del texto francés nos permite fechar aproximadamente dicho texto de base: en efecto, según se sabe por varias fuentes, los españoles llegaron al Cuzco el 18 de noviembre de 1533, pero sobre este acontecimiento nada dicen las Nouvelles. No obstante, puesto que dan cuenta de la muerte de Atahualpa a fines de julio y del inicio de la expedición al Cuzco a comienzos de agosto, es probable que las noticias del Perú llegaran a Panamá entre agosto y noviembre del 33. La relación basada en ellas llegaría a Europa a fines del 33 o a comienzos del 34 , lo que corresponde a los primeros relatos publicados en Italia y Alemania.

Un examen detallado (cf. nota 1) muestra que el texto de Lyon no deja de tener interés para la historia del léxico francés, pues contiene una serie de primeras documentaciones: alentour (grafia); aposter "relever des troupes dans un mauvais dessein"; atabale "tambourin de cuivre"; se faire tirer

10 Hay varios indicios lingüísticos que apuntan al texto espafiol de base: la grafia Peru, escrita a la española, varias palabras españolas, algunas de ellas préstamos americanos recientes, y otros calcos: p. e., «l'espesseur de demy doigt» proviene de «de medio dedo» [12]. El autor, por lo demás, se dirige a Vuestra Majestad, es decir, al rey de España, las vasijas están hechas al modo de las tinas de España [12] y el texto se termina por el país de Castilla.

11 Op. cit., págs. 5-56.

12 Véase para más detalles Dietrich Brisemeister, «Frühe Berichte über die spanische Eroberung in deutschen Ubersetzungen des 16 . Jahrhunderts», en Der eroberte Kontinent, Historische Realität, Rechtfertigung und literarische Darstellung der Kolonisation Amerikas, ed. por Karl Kohut et al., Frankfurt, Vervuert, 1991, págs. 246-259.

13 Porras Barrenechea, op. cit., pág. 34. 
l'aureille ; bataillon ; cacique ; casse "caisse"; chapelet "especie de soporte"; mais, maravédis; miraculeux; racoustrer; reste [de una tropa]; rondelle (ya en 1527 en una traducción de La Celestina); Vostre Majesté.

En cuanto a la región de origen del traductor todo habla en favor del sureste de Francia, y el hecho de que el texto haya sido impreso en Lyon no es, por cierto, azaroso, cuanto más que Lyon parece haber tenido buenos contactos no sólo con Italia sino también con España (notemos, al margen, que la edición príncipe del Lexicon... dictionarium... ex hispaniense in gallicum traductum eloquium de Nebrija se imprimió en Lyon en 1511. iY el único ejemplar conocido se encuentra hoy en el British Museum!). El autor de nuestra traducción era también, muy probablemente, de la región francoprovenzal, y hasta podría decirse: quizás del Delfinado. La palabra tupin "pot" es típica del sureste y pollin (que corresponde al esp. pollino) tiene el sentido de asno solamente en el antiguo dialecto de dicha región. Están expresamente atestiguados en este dialecto, por ejemplo, extime, carquès, matras, fiole, compaignon, estimer. La forma couvecle ( $\sin r$ ) está bien documentada en los patois del sureste (Sav. Chambéry). Mulet es particularmente frecuente en francoprovenzal, raro en provenzal ${ }^{14}$. Un último caso -dudoso, es verdad-: "deux fardeaux d'or au [1. où?] il y a tout plain de petites piesses pesant huict quintaulx" [13]. ¿ Simple error de imprenta? Pero $a u$ "où" < $u b i$ está atestiguado en el sureste, en la antigua Bresse.

Queda el título: que se hable de las islas del Perú admirará únicamente a quien no esté familiarizado con la cosmografía del siglo xvi. Frank Lestringant, el mejor conocedor actual de las concepciones geográficas de esta época, hace un resumen sucinto en un capitulo sobre los islarios (fr. insulaire):

On appelle Insulaire (Isolario, en italien) un atlas exclusivement composé de cartes et de descriptions d'îles. Ce genre qui connut un certain essor du $15 \mathrm{e}$ au $18 \mathrm{e}$ siècle a pour origine l'ordre suivi dans la description du monde par l'ancienne géographie héritée de Ptolémée et de Strabon, qui traitait, en des chapitres séparés, des "terres continentes" et des fles. Une telle dichotomie était posée comme fondamentale, dans la mesure où elle impliquait, pardelà la différence du dessin et des contours - ouverts pour les continents, fermés pour les lles et péninsules-, une distinction de nature.

Nous en voyons la preuve dans les mappe-mondes médiévales, où les îles sont souvent peintes d'une autre couleur que les masses continentales. Leurs contours geométriques simples les distinguent encore des frontières imprécises et irrégulières réservées aux terres fermes. Ainsi les "insulae" vertes du Beatus de Saint-Sever (11e siècle) s'apparentent plus à l'ovale des poissons bleus qui s'entrecroisent dans leur intervalle, qu'à la surface ocre de l'unique continent formé par la soudure en un même arc de terre de l'Europe, de l'Asie et de l'Afrique. L'ile apparait en quelque sorte contaminee par le

14 Cfr. FEW 6³ pág. 212a. 
milieu marin où elle s'insère. C'est qu'elle revêt une ambiguïté constitutive: formée de terre, l'ile se définit néanmoins par la mer ou le lac qui l'entoure. Sa nature est donc essentiellement hybride ${ }^{15}$.

Justamente en este marco se sitúan los 'grandes descubrimientos':

L'ère des grandes découvertes, au lieu d'élargir par explorations contiguës l'espace traditionnel de l'oekoumène (terre connue des Anciens et, par eux, seule réputée habitable), a vu tout d'abord se multiplier les îles: Quiloa, Mombasa, Zanzibar, Goa sur la route orientale des épices; archipel des Antilles où aborde Colomb, Terre Neuve de Cabot et Cartier, mais aussi le Pérou et le Brésil longtemps réputés insulaires ${ }^{16}$; et l'Amérique elle-même qui figure dans maint Isolario comme la plus grande des îles du monde. Les premiers voyages transocéaniques ont donc eu pour résultat immédiat d'émietter en quelque sorte l'image de la terre - jadis faite de trois continents solidaires et étroitement rassemblés autour de l'échancrure méditerranéenne- en une poussière d'îlots: archipel innombrable en quoi se résout l'éclatement géographique de l'ancien monde, et dont les découvertes ultérieures vont progressivement ressouder les éléments épars. C'est ainsi qu'il faudra des décennies pour que, du nord au sud, soit reconstituée l'unité du continent américain. Auparavant, les explorateurs successifs de la côte du Nouveau Monde - Colomb, Verrazano, Cartier ou Vespucci- auront recherché vainement de l'estuaire du Saint-Laurent à celui de La Plata, la solution de continuité permettant, en même temps que l'accès direct aux royaumes d'Orient, Ia rupture en une chaîne d'îles de la barrière littorale ainsi opposée ${ }^{17}$.

Desde 1493, Basilea — donde se publicó desde ese año una carta de Cristóbal Colón en latín- se convirtió en un importante centro de irradiación de las noticias concernientes a las 'indias occidentales'. En esto participaba incluso Sebastian Brant, profesor de literatura latina y de derecho en Basilea, donde se publicó en 1494 su Nave de los locos (Narrenschiff). Se hablaba de las islas de oro (Goldinseln) y de gente desnuda (nacket Lüt). A esto siguió el descubrimiento de las 'nuevas islas'. Pero es en Venecia donde se publicaron los grandes atlas de las islas de los siglos xvI y xvII. Dice Lestringant: "Archipel de 138 îlots, 1'espace insulaire de Venise devient le paradigme dont s'autorise un cartographe tel que Coronelli pour décrire les îles du monde entier ${ }^{18}$. Venise "préside... a l'ensemble des îles du globo, parmi lesquelles figurent, chez Bordone [1628] et Porcacchi [1572], les con-

15 F. Lestringant, «Insulaires», en Cartes et Figures de la terre, Paris, Centre Georges Pompidou, 1980, pág. 470.

${ }_{16}$ Vid. también el mapa Océan fermé et Brésil insulaire: un monde conforme a la vision d'André Thévet. D'après Paolo Forlani et Ferrando Bertelli, Universale Descrittione di tutta la terra conosciuta fin qui, 1565 (mapa reproducido por Frank Lestringant, en Le Huguenot et le Sauvage, Paris, 1990, pág. 221).

17 Ib., pág. 471.

18 Ib., págs. 471 y sig. 
tours insularisées de l'Inde et du Nouveau Monde" ${ }^{19}$. En este contexto se inscriben no solamente la Cosmographie Universelle de André Thevet $(1575)^{20}$, el mito amazónico de la isla Imeugle, poblada de mujeres, y de la isla Inebile, poblada de hombres ${ }^{21}$, sino también, por ejemplo, la obra de Simon Grün (Gruenaeus) Novus orbis... insularum impreso en Basilea, el Quart Livre de Rabelais ${ }^{22}$, Juan de la Peña, De Bello contra Insulanos $(1564 / 1565)^{23}$ y, por cierto, nuestras Nouvelles certaines des Isles du Peru.

No hay que admirarse, pues, de que aún a fines del siglo xvi, esta concepción siga viva: incluso para Nicot, en 1606, la palabra Pérou, escrita todavía Péru, se define como "un païs des isles occidentales, ainsi nommé d'une rivière qui a de largeur environ une lieue" ${ }^{24}$. El plural las Islas explica el plural las Indias.

A continuación publicamos la transcripción del texto francés y una traducción al español. En cuanto a la primera, resolvemos las abreviaturas, modernizamos la puntuación y hacemos uso de apóstrofos; entre corchetes indicamos las enmiendas. La división por párrafos corresponde a la que señalan las letras capitulares y los calderones del original, salvo en el caso del inventario de objetos, que presentamos en forma de lista.

La traducción, que ciertamente no tiene la pretensión de reconstruir, ni siquiera fragmentariamente, la lengua del texto de base - por más que en algún caso se hayan tomado en cuenta los usos de época- sigue de cerca el texto francés y respeta, en general, su sintaxis repetitiva y redundante. No obstante, se han suprimido en algunos casos ciertas expresiones tautológicas, a fin de aligerar el discurso. Para facilitar la compulsa se indican entre corchetes los cambios de página, tal como lo hacemos en el texto de la transcripción. En las notas a pie de página se aclara la identidad o la forma de algunos topónimos y antropónimos, y se comentan asimismo algunos pro-

\footnotetext{
$10 \quad I b$. pág. 472.

20 Véase la reseña de K. B. en la ZRPh 102, 1986, págs. 424-428.

21 VEase Lestringant, op. cit., pág. 473.

22 V. Frank Lestringant, «L'insulaire de Rabelais, ou la fiction en archipel (Pour une lecture topographique du "Quart Livre")», en Etudes Rabelaisiennes. XXI, Ginebra, 1988, págs. 249-274.

${ }^{23}$ Ed. L. Pereña et al., Madrid, 1982; véase la reseña de K. B. en la ZRPh 99, 1983, págs. 684686 .

24 Thrésor de la langue trançoyse, citado por Colette Demaizière, «Le vocabulaire exotique sans le dictionnaire de Jean Nicot», en Exotisme et création, Actes du Colloque International, Lyon, 1983, Lyon, Université Jean Moulin, 1985, págs. 17-27, esp., pág. 22. Para la repercusión de los grandes descubrimientos en Europa véase, entre otras, las obras de Frauke Gewecke, Wie die neue Welt in die alte kam, Stuttgart, KlettCotta, 1986 (obra seria a pesar del título algo pueril, cf. la resefia de K. B. en ZRPh 103, 1987, págs. 458-459); y en un marco incluso más vasto Urs Bitterli, Die Entdeckung Amerikas, Von Kolumbus bis Alexander von Humboldt, München, Beck, 2.' ed., 1992.
} 
blemas de interpretación o algunas opciones adoptadas. P. B. se refiere a la versión de Raúl Porras Barrenechea, ya mencionada. La presente traducción corrige, en muy numerosos casos, que no se comentan cada vez, los errores de dicha versión; sólo se llama la atención sobre los de mayor significación histórica o lingüistica.

De este modo, creemos haber contribuido a revalorizar estas antiguas Nouvelles sobre el Perú, de mucho interés tanto para historiadores como para romanistas.

\section{NOUVELLES CERTAINES DES ISLES DU PERU 1534}

On les vend a Lyon ches Françoys Juste devant Nostre dame de Confort.

S'ensuyvent les letres de Françoys Pizarro, gouverneur du riche pays et province nommee le Peru, faisant mention des merveilleuses choses tant veuez par ces ${ }^{1}$ proprez yeulx que par letres a luy envoyees par ceulx que au mesme pays habitent, aux quelles sont contenues plusieurs choses nouvelles tant des richesses inextimables d'or et d'argent et pierres precieuses en celle province trouvees et d'icelluy pays emenees que de plusieurs aultres marchandises et richesses; et ce despuis le temps qu'il monta sur mer jusques a present.

C'est ainsi que le gouverneur Françoys Pizarro, dès l'heure qu'il arrivast et mist le pied a terre dens la province nommee le Port Vieulx, lequel est le premier pays par le mesme gouverneur trouvé et descouvert en ycelles regions. En aprés, ledict gouverneur se partit de ce lieu et print son chemin vers une aultre province, laquelle ilz nomment Coliaque, en laquelle est une cité que est nommee semblablement Coliaque, et le seigneur d'icelle a aussi ce mesme nom. Les maisons d'icelle cité sont toutes de pierre fort bien massonnees, mais la couverture est de paille. Arrivez les Chrestiens au devant de la cité luy commançarent a bailler l'assault. Le seigneur d'icelle, lequel estoit vaillant et exercité en la guerre, estant desja adverty du cas, a cause que il n'avoit jamais veu aulcuns chrestiens ne jamais n'en avoit ouy parlé, leur [2] envoya vingt mille castillans de fin or avecq plusieurs aultres beaulx joyaulx. En ce lieu furent trouvees grande quantité d'esmerauldes; et pource que les chrestiens ne les cognoissoyent point, ilz les rompoyent et gastoient. En ce mesme lieu se arrestarent les Chrestiens par l'espace de six moys

1 Las graflas $c$ y $s$ se confunden a menudo, sobre todo ses y ces: ces propres yeulx [1], entre ces mains [7], ces gens [4], ces principaulx Caciques [6], ce faisoit [6], $c e$ voyant prisonnier [8]; al revés, se encuentra $s$ por $c$ : se temps [1], seinctures [6]. 
soy repousant et faisant bonne chiere. Les six moys avoir esté passés, le gouverneur avecq ses gens prindrent leur chemin le long de la coste de la mer par terre, et les navires par la mer, bien cent cinquante lieux, et vindrent au devant d'eulx plusieurs Caciques traicter paix avecq eulx, en leur faisant plusieurs dons d'or et d'argent, en sorte qu'ilz eurent plus de trente mille besans d'or. Oultreplus leur firent present d'un grand nombre d'hommes Indians pour les servir avecq force vituaille. En aprés sont arrivez en une isle que est bien a une lieu de terre ferme, laquelle est grande a merveilles. C'est un grand seigneur celluy qui est seigneur d'icelle. Les habitans d'icelle, tant hommes que femmes, sont beaulx de visage et de bonne stature et bien puissans; avecq le seigneur d'icelle sont plusieurs aultres grandz seigneurs. L'isle est nommee la Pinassa. Le seigneur est nommé Tummeba; ce seigneur cy tient plusieurs grandz vaisseaulx sur mer, faictz comme petites navires, lequel vint sur ces vaisseaux avecq grant nombre de gens veoir le capitaine, en luy portant grande quantité de vivres a la coustume du pays, et le pria que luy pleust de s'en venir avecq luy en l'isle sus ceste maniere de bateaux, a laquelle chose le capitaine consentit et s'en allerent avecq luy, où demeurarent avecq ce peuple par l'espace de deux moys, et [3] leur faisoyent manger des oysons du pays, lesquelz sont semblables aux canes privees de Castille, reste que sont tresplus grands, et plusieurs aultres sortes de viandes du pays. Et comme ainsi soit que les espaignolz en tous lieux et places ou ilz soy rencontrent soyent oultrés et aulcunement desordonnez, specialement enverz les femmes; pour ceste cause et pource qu'ilz traictent trop mal les habitans de l'isle, deliberarent entre eulx les Indiens de ceste isle de tuer tous les Chrestiens. Le gouverneur estre adverty du cas, print prisonnier le seigneur d'icelle avecq les plus principaulx, a l'occasion de quoy s'esmeut tresgrande guerre entre les Indiens et les Chrestiens, pour ce que les Indiens sont gens puissans et hardies en faictz de guerre; toutes foys, il y mourut grand nombre d'Indiens sans qu'il en mourut des Chrestiens fors que un. Les Indiens voyant la grand perte et dommaige qu'ilz avoyent eu, traictarent la paix avecq les chrestiens, en leur promettant grand quantité d'or et d'argent pour la rançon de leur seigneur. Le gouverneur ce voyant leur deslivra leur seigneur et quant et quant les aultres prisonniers; laquelle chose faicte tout le commun se esleva, mais les chrestiens se misrent en defense contre les Indiens, en telle sorte que les Indiens ne trovoyent aultre remede sinon s'en fouir aux montaignes et soy cacher aux cavernes.

Ce faict, les Chrestiens se sont partis de là et s'en sont allez a la terre ferme sur navires et aultres manieres de vaisseaux que ilz nomment Balsas, et arriverent en une cité nommee Tumbez, de laquelle le seigneur est un Cacique nommé Chilemeza, au quel le gouver[4]neur estant en la susdicte Isle, avoit envoyé huyct cens prisonniers, et davantaige, tant masles que 
femelles, lesquelz il avoit prins du seigneur de ceste Isle. Mais ledict Chilemeza, ce voyant, ne luy sembloit pas trop beau, et doubtant qu'il n'eust la venue, se esmeut et tout le pays avecq luy a l'encontre des Chrestiens, laquelle chose fust cause que le gouverneur entra dans le pays dudict Chilemeza destruysant le pays et mettant a mort plusieurs gens. Le Cacique, voyant le grand dommaige et destruction que les Chrestiens faisoient par tout le pays, il s'accorda et fist paix avecq les Chrestiens, et le gouverneur en feut content et laissa en la dicte cité de Tumbez cinquante espaignolz. Aprés que ce fust faict, le gouverneur s'en alla avecq les gens qu'il avoit de reste pour visiter et descouvrir ledict pays, et alla tant par ses journees qu'il arriva a une riviere qu'on appelle sainct Michel, au pres di quel y a plusieurs villes et villaiges d'Indiens, et aupres d'icelle riviere est une belle, grande et haulte maison de pierre faicte en façon de forteresse, aupres de laquelle maison y a une grand et belle cité de laquelle le vindrent au devant des Chrestiens plusieurs Caciques avecq force vivres. Les Chrestiens commencerent a manger et soy repouser, et aprés qu'ilz eurent prinse [sic] leur refection, les Caciques les menerent loger en ceste forteresse. Le gouverneur estant en la forteresse sortit avecq la moytié de ces [1. ses] gens pour visiter le pays le long de la riviere, lequel trouva que la terre estoit bonne et fertille, et a ceste cause il feist faire une bourgade de Chrestiens, et fut le premier que fust jamais faict en ce pays, laquelle est [5] nommee sainct Michel. Les Indiens sont grandz amys des Chrestiens, et la riviere est grande, et on la passe par bateaulx.

De ce lieu se partit le gouverneur, laissant en ceste bourgade quarante Chrestiens, et amena avecq luy cent et cinquante hommes de guerre, entre lesquelz y en avoit septente a cheval et ce pour s'enquerre d'un grand seigneur du quel tous les seigneurs des pays circunvoisins estoyent subiectz, lequel estoit nommé Tabalica qui estoit bien quatre vingtz lieux loing du lieu dessus dict. Il raconte que le chemin par ou on y va contient de largeur huyct pas et est fort net, et d'un cousté et d'aultre du chemin y a de [1. une] muraille de terre de l'aulteur d'une toyse, et de quatre en quatre lieues une maison forte faicte de pierre environnee de muraille de l'aulteur de deux toyses couverte de l'extremité des canes. Il y a plusieurs Caciques le long de ce chemin, ayant un chascun soubz luy de quinze a vingt mille Indiens. En poursuyvant ledict chemin ilz apperceurent sus une aulte montaigne fort fertille une grand forteresse faicte de pierre tresbien bastie, et ladicte montaigne bien peuplee et habitee d'Indiens ${ }^{2}$; les Chrestiens prindrent leur chemin le long de ceste montaigne jusques a ce qu'ilz apperceurent une grand cité qu'est appellee Caxamalca, et ce mesme jour le gouverneur fust

2 Dindiens repetidas veces; también Despaigne [12]. 
logé une lieu et demye de ceste cité de Caxamalca. Le gouverneur estant en ce lieu envoya un messagier par devers ledict Atabalica, lequel estoit en une maison de plaisance a une lietue de la cité, au devant de laq[ue]lle maison scelon que dizent passe une grand riviere; tout alentour de ladicte maison estoit grand [6] nombre de gens dudict Atabalica avecq plusieurs tentes et pavillons, que on eust dist que c'estoit un camp. Incontinent que le dict Atabalica eust entendu le messagier du gouverneur, sans faire delay envoya un de ces [1. ses] ${ }^{1}$ principaulx Caciques nommé Capo luy signifier qu'il s'en allasse louger en la cité de Caxamalca et que il luy envoyeroit tout ce que luy feroit mestier touchant le boyre et le manger et que le jour ensuyvant de bon matin il seroit avecq luy. Voyant le gouverneur que le jour estoit passé, et encores un aultre, et ledict Atabalica ne venoit point, il eut craincte de sa demeure, lequel incontinent envoya vers son frere Fernand Pizarro quinze hommes a cheval pour luy signifier tout ce que ce $[1 \text {. se }]^{1}$ faisoit, et que luy pleust de le venir veoir astivement, laquelle chose il feit sans delay. Le mesme jour Atabalica adressa son chemin pour venir a la cité de Caxamalca et y arriva sus le soir, lequel estant dans une litiere toute garnie de fin or vint veoir le gouverneur, et le portoyent plusieurs Caciques. Il y avoit au devant de luy plusieurs Indiens qui nettoyent le chemin, jasoyt qu'il fust asses net, et qu'il n'y eust riens a nettoyer. Aprés il en y avoit d'aultres plusieurs, desquelz les uns chantoyent, et les aultres dansoyent; tout a l'entour de luy y avoit grand nombre d'Indiens qu'ilz nomment $\mathrm{Ga}[\mathrm{n}]$ dules $^{3}$ qui estoyent pour sa garde, portant les uns des Aches d'armes, les aultres des Alebardes faictes d'argent, et de grosses Massues pendues a leurs seinctures. De rechief, il y avoit un grand bataillon de ces $\mathrm{Ga}[\mathrm{n}] \mathrm{dules}^{3}$, ou il $\mathrm{y}$ avoit grand nombre de gens tous armez portant Javelines, arcz et flesches; et aussi un aultre pareil bataillon de ces [7] mesmes $\mathrm{Ga}$ [n]dules ${ }^{3}$ armés de mesme come les aultres d'un aultre cousté. En ceste sorte entra Atabalica en la cité laissant de rechief sur les champs un grand nombre de gens qui estoient scelon que me fut raporté plus de quarante mille $\mathrm{Ga}[\mathrm{n}]-$ dules ${ }^{3}$ portant picques de vingt piedz de long sans les Haches, Alebardes et Massues et frondes. A ses gens qu'estoyent sur les champs scelon que je apperceuz despuis il leur avoit comandé qu'une partie d'eulx s'en allast mettre en embuche de une part de la cité de Caxamalca et l'aultre de l'aultre, a celle fin que quand il s'approcheroit de la cité si les Chrestiens s'en vouloyent fouyr qu'ilz fussent enserrez de tous coustez, et luy sembloit qu'il les tenoit desja en sa main.

Le gouverneur, voyant que Atabalica venoit a la cité, il feist mettre tous ses gens en ordre, tant de pied que a cheval, et en feist deux parties; aprés

\footnotetext{
3 Cf. la nota 15 de la traducción.
} 
ce faict, il envoya un heaupere de l'ordre de sainct Dominique, lequel se nommoit frere Vincent, pour parler audict Atabalica, lequel beaupere luy parla, et portoyt en ses mains un livre, ou estoyent les Evangiles, et dict a Atabalica que les choses que estoyent escriptes en ce livre, c'estoit ce que dieu leur commandoyt de faire. Adoncq Atabalica luy dict qu'il luy montrast le livre, laquelle chose il feist, et incontinent qu'il l'eut entre ces [1. ses] ${ }^{1}$ mains, il le jecta en terre. Ledict beaupere le releva de terre et s'en retourna vers le gouverneur criant a aulte voix et disant qu'il failloit exaulcer la foy de Jesuchrist. Ce ouy le gouverneur, sortit tout armé tenant une espee et une rondelle en ces [1. ses] ${ }^{1}$ mains, et ce a pied, et avecq luy tous les gens qu'il avoit, tant de pied que a cheval. Arrivé le gouverneur où ledict Atabalica estoit, luy [8] mist la main de sus et le jecta hors de la où il estoit, et les aultres Chrestiens commencerent a mettre a mort tous ceulx que le portoyent et vont d'un grand couraige donner dedans le bataillon des Indiens où ilz misrent a mort grand nombre d'eulx, et dura la batterie despuis vespres jusques a ce qu'il fust nuyt, où ilz prindrent plusieurs des principaulx des Indiens. La despouille d'eulx que fut alors prinse, est extimee quarante mille castillens d'or et trente mille marcz d'argent, et en eussions heu davantaige, mais pource qu'il estoit nuyct, les Indiens qui s'enfuyoient emporterent le demourant toute la nuyct. Ledict Atabalica, ce [1. se $]^{1}$ voyant prisonnier et craignant d'estre mis a mort, promist aux Chrestiens leur donner une maison plaine d'or de vingt piedz d'aulteur et de dix et huyct de largeur, laquelle chose fust faicte comme l'avoit promis, et monte en somme tout l'or qui estoit en ceste maison comme d'aultre qu'il y feist mettre troys millions de castillens; et de rechief donna si grant quantité d'argent que ne se sçauroyt nombrer. De laquelle somme il en appartient a vostre majesté de vostre droict troys cens mille Pesos de bon or vaillant ung chascun de ces Pesos quatre cens et cinquante maravediz, de laquelle somme vous porte a ceste heure Fernand Pizarro cent cinquante mille Pesos d'or et cinq mille marcz d'argent; il ne vous n'apporte point davantaige pour ce que il n'a point navires en quoy il le puisse porter. C'est une chose miraculeuse, a ouyr dire, pour ce que en partissant ce tresor il advint a chascun homme de cheval pour sa part dix mille castillens d'or et troys cens et cinquante marcz d'argent, et a chascun homme de pied cinq mille castillens d'or et cent soixantecinq [9] marcz d'argent.

Ce pendant que ces choses passoyent et que le gouverneur tenoit prisonnier Atabalica, il envoya dire a Antoyne [1. Fernand] Pizarro qu'il print une quantité de gens de cheval et qu'il s'en allast enquerre d'un aultre grand seigneur de plusgrande puissance et richesse que n'est Atabalica, lequel on appelle le Cusque, lequel est frere dudict Atabalica et habite en une seigneurie et pays le plus riche que soit en tout le monde. Il y a en ce pays une maison 
d'oraison, de laquelle les paroys sont toutes d'or et d'argent et la nomment la maison du soleil, laquelle maison gardent plusieurs gens de guerre. Ilz disent que c'est le pays le plus fertille et plaisant qu'on sçauroyt trouver. Les chemins sont fort larges et netz, et de lieue en lieue il y a des pilliers, et en ung chascun pillier $\mathrm{y}$ a un indien en poste attendant aulcunes nouvelles, lequel voyant quelcun s'en va criant a aulte voix signifiant a l'autre la cause pourquoy il va; et l'autre luy faict signe qu'il l'a bien entendu, descend de où il est monté et va courant jusques a l'aultre pillier, et l'aultre remonte au mesme pillier d'ou l'aultre est descendu, et en sorte que les seigneurs de cest pays sçavent ce qu'ilz veullent en brief temps.

Arrivant Fernand Pizarro où ledit Cusque habitoyt luy fust dict que il estoit mort a cause que son frere Atabalica l'avoyt faict mourir avecq poyson. En ceste province icy il y a de tresgrandes et puissantes rivieres, sur lesquelles il y a de pontz faictz de grosses cordes et entre l'une et l'aultre il y a de cordes plus desliees tissues en fasson d'un fillé bien serré et menu; et de ces pontz il en y a deux, par où passent les seigneurs et l'aultre par où passent le commun populaire. Par tous les chemins [10] d'un cousté et d'aultre il y a une muraille faicte de terre. Il y a d'un chascun cousté du pont gens qui habitent là mesme que n'ont aultre office ne charge sinon a reparer et racoustrer les pontz, et dès incontinent que une corde se gaste ou est rompue y en remettre une aultre. Fernand Pizarro de ce voyage a raporté de si grandes et merveilleuses nouvelles qu'il est quasi impossible a persuader. Ce pendant que ces choses passoient et que le gouverneur estoyt en la cité de Caxamalca, le dict Atabalica pourchassoit de mectre a mort tous les Chrestiens, et a ce faire avoit apostez quatre mille Ga[n]dule $[\mathrm{s}]^{3}$, tous gens de guerre; de laquelle chose le gouverneur fust adverty pour les Indiens de la cité Caxamalca, lequel sçachant de certain la chose estre verifiee et mesmement par la confession dudict Atabalica, fust condenné ledict Atabalica a estre bruslé, lequel Atabalica requist estre faict Chrestien, et qu'il vouloit mourir comme bon Chrestien et demanda estre baptizé, laquelle chose fut faicte; et avoir esté baptizé il recommanda son ame a dieu; lequel premierement on estrangla, et aprés le brusla on. Il advint aprés que il avoit un aultre frere qui estoit encores jeune lequel vint au gouverneur luy priant qu'il luy pleust luy donner letre de estre seigneur du pays de son pere, pource que il en estoit heritier, et que il vouloit estre subject a vostre majesté et servir aux chrestiens. Le gouverneur ayant faict promettre la foy, luy ottroya le tiltre de seigneur du pays et seigneurie de son pere au nom de vostre majesté, lequel incontinent promist de faire un present au gouverneur, d'une grand quantité d'or.

Ces choses faictes, le gouverneur se despartist pour al- [11] ler a Xaxuxa [1. Xauxa] et Chincha que sont deux grandes cités, situees en la meilleure 
contree de tout le pays, et avoit deliberé de faire une bourgade a vingt lieues du port de mer où les chrestiens habiteroyent; mais incontinent que ces cités eurent les nouvelles de la mort dudict Atabalica ilz vindrent au devant du gouverneur avecq grand quantité d'or et d'argent, et ce pour luy en faire ung present pour ce que ilz estoyent fort joyeulx de la mort de Atabalica, pour ce qu'ilz luy vouloyent grand mal. Le gouverneur les remercia grandement et ne le voulut poinct recepvoir; et leur dict que ilz le raportassent avecq eulx, car il avoit deliberé d'aller veoir ces deux cités et là il le recepvroit, laquelle chose ilz firent. Les caciques que [sic] cest or portoyent entre les piesses que y estoient il y avoit quatre brebis d'or de la grandeur des brebis du pays que sont de la grandeur d'un pollin de cinq ou six moys et avecq icelles deux pasteurs d'or de la grandeur de petis hommes. Item une fontaine d'or si bien faicte que estoit possible, pesant dixhuyct mille besans d'or, en la quelle Atabalica avoit de coustume se laver. Il y a en ceste province du Peru en plusieurs lieux mines d'or fort riches desquelles on ha tiré piesses de fin or pesant douze et quinze livres, et aulcunes de plus et aultres de moins. Cest or est de vingt et vingt un quilates; cest or est si fin que pour en faire aulcunes piesses, et affin qu'il soit plus fort, ilz le meslent avecq d'argent ou cuyvre. Les hommes sont vestus a leur coustume. Les femmes sont couvertes jusques aux piedz et ont les bras descouvers. Ilz disent que elles sont plus blanches que ne sont les Indienes que sont en Espaigne. Les grands seigneurs [12] du pays portent de belles chemises bien labourees et par dessus des manteaulx que leur couvrent la teste et les attachent au dessoulz de la barbe; en laquelle chose on congnoist les grands seigneurs entre les aultres. Les chrestiens ont desja eu nouvelles d'un aultre pays qu'est delà deux cens lieues; et disent les Indiens qu'il y a encores de plus grands richesses d'or et d'argent et pierres precieuses que au pays là où ilz sont, et disent que les gens du pays sont fort grands a merveilles comme geans et sont fort vaillans en guerre et qu'ilz usent d'une certaine herbe qu'ilz mettent aux flesches quand ilz tirent, et que les chemins du pays sont fort beaulx et larges et que en plusieurs lieux ilz portent souliers d'or et d'argent, on ne sçait pas pour vray sinon par le rapport des Indiens du pays.

Memoire des choses et piesses tant d'or que d'argent qu'on apporte en Espaigne, et je pense que c'est pour faire un present a vostre majesté.

Premierement vingt et quatre vaisseaux faictz a mode de tines d'Espaigne contenant chascun sept seaux et demy d'eaue, et encores plus que moins, de l'espesseur de demy doigt, et semble qu'il y a grand quantité d'or en leur faczon.

Item treize planches ou platines d'or tant grandes que petites de la mesme espesseur dessusdicte, et en usent a garnir lurs portes et aulcuns bancs. 
Item cinquante petis platz d'or pour servir a table.

Item deux grands platz d'or.

Item un aultre grand plat d'or.

Item vingt et quatre escuelles a aureille de fin or.

Item huyct charges d'or en seize fardeaux que poysent soixante et quatre quintaulx, et sont petites piesses, et pource que n'avons voulı [13] deslier les fardeaux, n'avons point veu les piesses que sont dedens.

Item deux grands sacz faictz d'or de la fasson des sacz de laboureux que contienent chascun deux bi[c]het de froment.

Item aultres deux fardeaux d'or au [1. où] il $\mathrm{y}$ a tout plain de petites piesses pesant huict quintaulx.

Item dixhuyct aultres planches d'or tant petites que grandes.

Item une femme faicte d'or et d'argent.

Item deux petites casses d'or.

Item deux grans limassons d'or.

Item vingt chappons que grans que petis d'or, un chascun pesant cent pesos.

Item un escriptoire avecq sa plume, le tout d'or.

Item troys petis bassins d'or.

Item troys couvecles d'or de ces vaisseaulx qu'ilz appellent tines d'or.

Item six aultres grands platz d'or.

Item deux couvecles de tupins d'or.

Item une autre petite casse d'or.

Item quatre lunettes d'or.

Item troys aultres couvecles de tines d'or.

Item deux fontaynes d'or.

Item deux medailles d'or ou est la pourtraicture du Cusque, et de sa femme, le tout mis dens une boyte d'argent.

Item un homme d'or de l'aulteur d'un enfant de dix ans.

Item deux lictz ${ }^{4}$ de maiz et $\mathrm{y}$ a en chascune deux mazor[ques] d'or.

Item deux carquès d'or pour porter matras et flesches.

Item un mirouer d'or.

Item aultres troys platz d'or.

Item deux Atabales d'or desquelz ilz usent en la guerre comme nous de taborins de suisse, pesant cent et vingt marz d'or.

Item deux chappo[n]s d'or esmaisltez.

Item deux grands tupins d'or.

Item une petite casse d'or.

Item un petit bassin d'or.

- Cf. la nota 24 de la traducción. 
Item deux grandes fioles d'or.

Item deux chasteaux moyens d'or.

Item aultres deux fontaynes d'or [14].

Item une culiere d'or.

Item un pot a vin d'or.

Item un aultre bassin d'or.

Item XXII chemises oeuvrees d'or et d'argent et avecq plumes a la mode du pays.

Item XXVII manteaux de la plus estrange faczon qu'il est possible de veoir.

Item ilz portent quarante huyct vaisseaux d'argent qu'ilz appellent tines, contenant chascun sept seaux et demy de l'espesseur d'un doigt, en sorte que un mulet estoit bien chargé d'en porter deux de ces vaisseaux.

Item cinquante platz petis d'argent pour servir a table.

Item deux platz moyens d'argent.

Item un grand plat d'argent.

Item XXIIII petis platz d'argent.

Item un pot d'argent faict a la mode du pays.

Item un chapelet sur quoy on met les platz sur table d'argent.

Item deux fontaynes d'argent.

Item deux tupins d'argent.

Item deux aultres fontaynes d'argent esmaillees.

Item deux chappons esmaillés d'argent.

Item un aultre plat d'argent.

Monsieur, ilz s'en vont vingt et deux ou vingt et troys hommes que on[t] esté en ceste guerre, desquelz aulcuns portent vingt mille besans d'or, aulcuns dishuyct, aulcuns seize, et celluy qui en porte le moins est dix mille besans. Fernan Pizarro touchant ce que nous avons veu porté, en porte plus de LXXX pesos d'or, sans cela que il porte secretement.

Monsieur, il me semble estre licite et convenable que sçachez, combien prisent et extiment l'or ceulx que sont en la province nommee le Peru. Vous debvez sçavoir qu'il estoient deux compaignons, et l'ung des deux demanda a emprumpter deux mille castillens a l'aultre, et laquelle chose l'aultre fist. Celluy que les avoit emprumtés ayant faict ce qu'il [15] en avoit affaire, les voulut retourner a l'aultre en bon or. Celluy que les avoit prestez dist a l'aultre qu'il les guardasse encores, car pour le present il ne les povoit point recepvoir. Celluy que les avoit emprumptés le requiert devant tesmoings par plusieurs foys que il les receust, et laquelle chose l'aultre jamais ne voulut. Adoncq il s'en alla vers la Justice et le fist requerir qu'il reprinse son argent, lequel respondit priant le juge que luy pleust ne les luy faire point reprendre pour ce que veu qu'il ne sçavoit où mettre ce qu'il avoit, 
comment pourroit il recepvoir ces deux mille ducatz, et qu'il fisse tant envers celluy qui les avoit qu'il les gardasse et qu'il ne les luy demanderoit jamais. Ilz se debatirent tant entre eulx deux, l'un se deffendant de les reprendre, et l'aultre les luy voulant tousjours rendre, jusques qu'ilz vindrent d'appoinctement par le moyen de leurs amys que pource qu'ilz alloyent tous deux a la cité de Caxamalca, que celluy qui avoit cest or de l'aultre, qu'il le portasse jusques a Caxamalca, et que arrivant a la cité celluy que les avoit emprumptés rendisse mille castillens a l'aultre, et qu'il retinse les aultres mille pour la peine qu'il avoit heu de les porter. Laquelle chose fust faicte si liberalement que encores celluy qui les avoit prestez luy sembloit que l'aultre luy faisoit force en luy faisant recepvoir ces mille castillens des deux mille. Je vous foys juge si on se feroit pleidier et tirer l'aureille pour une telle chose au pays de Castille.

Finis.

\section{NOTICIAS VERDADERAS DE LAS ISLAS DEL PERU 1534}

Se venden en Lyon en casa de François Juste frente a Notre Dame de Confort.

Siguen las cartas de Francisco Pizarro, gobernador del rico país y provincia llamada el Perú, las cuales mencionan las cosas maravillosas tanto vistas por sus propios ojos como por cartas enviadas a él por los que viven en el mismo país, en las cuales se contienen muchas cosas nuevas, tanto sobre las inestimables riquezas de oro y de plata y piedras preciosas encontradas en esta provincia y traídas de dicho país como de muchas otras mercaderías y riquezas, y todo esto desde el tiempo en que se hizo a la mar hasta el presente.

Es así como el gobernador Francisco Pizarro, desde el momento en que llegó y puso pie a tierra en la provincia llamada el Puerto Viejo, el cual es el primer país encontrado y descubierto por el propio gobernador en aquellas regiones. Después, dicho gobernador se fue de ese lugar y se dirigió hacia otra provincia, a la que llaman Coliaque ${ }^{1}$, en la cual está una ciudad llamada igualmente Coliaque, y el señor de aquella tiene también este mismo nombre.

\footnotetext{
1 Coaque.
} 
Las casas de esta ciudad son todas de piedra muy bien construidas, pero el techo es de paja. Llegados los cristianos delante de la ciudad comenzaron a darle asalto. El señor de ella, que era valiente y ejercitado en la guerra, estando ya advertido del caso, como no había visto nunca a ningún cristiano ni había oído jamás hablar de ellos, les [2] envió veinte mil castellanos de oro fino con muchas otras hermosas joyas. En este lugar fueron encontradas gran cantidad de esmeraldas, y como los cristianos no las conocian, las rompían y las echaban a perder. En este mismo lugar se detuvieron los cristianos por espacio de seis meses, descansando y comiendo bien. Pasados los seis meses, el gobernador con su gente emprendieron su camino a lo largo de la costa del mar por tierra, y los navios por el mar, unas ciento cincuenta leguas, y se llegaron a ellos muchos caciques a tratar la paz con ellos, haciéndoles muchos regalos de oro y plata, de suerte que obtuvieron más de treinta mil pesos ${ }^{2}$ de oro. Además les dieron como presente un gran número de hombres indios para servirlos y muchas vituallas. Luego llegaron a una isla que está por lo menos a una legua de tierra firme, la cual es extraordinariamente grande. Es un gran señor el que es señor de ella. Sus habitantes, tanto hombres como mujeres, son bellos de rostro y de buena estatura y muy fuertes; con el señor de la isla están muchos otros grandes señores. La isla es llamada Pinassa ${ }^{3}$. El señor es llamado Tummeba ${ }^{4}$; este señor tiene muchas embarcaciones grandes así como navíos pequeños hechos a la mar, el cual vino en estas embarcaciones con gran número de gente a ver al capitán, trayéndole gran cantidad de víveres a la usanza del país, y le rogó que aceptara venir con él a su isla en este tipo de barcos, cosa a la cual el capitán consintió y se fueron con él, donde vivieron con ese pueblo por espacio de dos meses, y [3] les hacían comer ansarones de la tierra ${ }^{5}$, que son parecidos a los patos domésticos de Castilla, salvo que son mucho más grandes, y muchos otros tipos de comidas del país. Y como quiera que los españoles en todos los lugares y sitios en que se encuentran sean exagerados y de algún modo desordenados, especialmente con las mujeres; por esta causa y porque tratan muy mal a los habitantes de la isla, decidieron los indios de esta isla matar a todos los cristianos. Siendo advertido del caso, el gobernador tomó prisionero al señor de ella con sus más principales, circunstancia de la que se suscitó una guerra muy grande entre los indios y los cristianos, porque los indios son gente fuerte y valerosa en asuntos de guerra. Sin embargo, murió un gran número de indios sin que de los cris-

2 Traducimos besant ( $<$ bizantium), nombre de la antigua moneda bizantina difundida en la Europa medieval, por peso, que es lo que se usa en los textos de la época.

3 La isla es La Puná en el golfo de Guayaquil.

4 En otras crónicas se lo llama Tumbala.

- Traducimos en este caso du pays por de la tierra, como se usa en los textos americanos desde antiguo para caracterizar a los especímenes de flora y fauna americanas. 
tianos muriese sino uno. Viendo los indios la gran pérdida y daño que habian recibido, trataron la paz con los cristianos, prometiéndoles gran cantidad de oro y plata por el rescate de su señor. Viendo esto, el gobernador puso en libertad a su señor y también a los otros prisioneros, hecho lo cual todo el pueblo se sublevó, pero los cristianos se defendieron contra los indios, de manera que los indios no tuvieron más remedio que huir a las montañas y esconderse en las cuevas.

Hecho esto, los cristianos partieron de alli y se fueron a la tierra firme en navíos y otros tipos de embarcaciones que ellos llaman balsas, y llegaron a una ciudad llamada Tumbes, de la cual el señor es un cacique llamado Chilemeza ${ }^{6}$, al cual el gobernador [4], estando en la susodicha isla, había enviado ochocientos prisioneros, y aún más, tanto hombres como mujeres que habian hecho prisioneros del señor de la isla. Pero al dicho Chilemeza, viendo esto, no le pareció muy bien, y previendo su venida, se alzó y todo el país con él contra los cristianos, lo cual fue causa de que el gobernador entrase en el pais del dicho Chilemeza destruyendo el país y matando mucha gente. El cacique, viendo el gran daño y destrucción que los cristianos hacian por todo el país, trató e hizo la paz con los cristianos, y el gobernador se alegró de ello y dejó en la dicha ciudad de Tumbes cincuenta españoles. Después de hecho esto, el gobernador se fue con la gente que le quedaba para visitar y descubrir dicho pais, y anduvo tantas jornadas que llegó a un río que se llama San Miguel $^{7}$, cerca del cual hay muchas villas y pueblos de indios, y cerca de dicho río hay una bella, grande y alta casa de piedra hecha como fortaleza, cerca de la cual hay una grande y bella ciudad de la cual vinieron ante los cristianos muchos caciques con muchos viveres. Los cristianos comenzaron a comer y a descansar, y después que hubieron comido, los caciques los llevaron a alojarse en esta fortaleza. Estando en la fortaleza, el gobernador salió con la mitad de su gente para visitar el país a lo largo del río, y encontró que la tierra era buena y fértil, y por ello hizo construir una aldea de cristianos, y fue la primera que se hizo en ese país, la cual es [5] llamada San Miguel ${ }^{8}$. Los indios son grandes amigos de los cristianos, el río es ancho y se lo cruza en barcos.

De este lugar partió el gobernador dejando en esta aldea a cuarenta cristianos, y llevó con él ciento cincuenta hombres de guerra, entre los cuales había setenta de a caballo, y esto para indagar sobre un gran señor del cual todos los señores de los países circunvecinos eran súbditos, el cual era

\footnotetext{
- En otras crónicas se lo llama Quilimasa o Chilimisa.

7 Se refiere al rfo Chira, antiguamente San Miguel.

- Se refiere a San Miguel de Tangarará, primera fundación peruana a la orilla norte de río Chira (ant. San Miguel). Esta ciudad fue desplazada dos veces, la segunda, a su emplazamiento actual, con el nombre de Piura.
} 
llamado Tabalica ${ }^{9}$, que estaba por lo menos a ochenta leguas del lugar susodicho. Cuenta que el camino por donde se va tiene ocho pasos de ancho y es muy limpio, y de un costado y de otro del camino hay una muralla de tierra de la altura de una toesa, y de cuatro en cuatro leguas una casa fuerte hecha de piedra, cercada de muralla de la altura de dos toesas cubierta con la punta de las cañas ${ }^{10}$. Hay muchos caciques a lo largo de este camino, y tiene cada uno bajo su mando de quince a veinte mil indios. Siguiendo dicho camino percibieron sobre otra montaña muy fértil una gran fortaleza hecha de piedra muy bien construida, y dicha montaña bien poblada $y$ habitada de indios; los cristianos tomaron su camino a lo largo de esta montaña hasta que vieron una gran ciudad que es llamada Caxamalca ${ }^{11}$ y ese mismo día el gobernador acampó a una legua y media de esta ciudad de Caxamalca. Estando en ese lugar, el gobernador envió a un mensajero al dicho Atabalica, el cual estaba en una casa de recreo a una legua de la ciudad, delante de la cual según dicen pasa un gran río; alrededor de dicha casa había un gran [6] número de gente del dicho Atabalica con muchas tiendas $^{12}$ y pabellones, que se hubiese dicho que era un campamento. Apenas el dicho Atabalica hubo escuchado al mensajero del gobernador, sin demora envió a uno de sus principales caciques llamado Capo ${ }^{13}$ a expresarle que fuese a alojarse en la ciudad de Caxamalca y que él le enviaría todo lo que le fuese menester para beber y comer y que al día siguiente temprano estaría con él. Viendo el gobernador que el día había pasado y aún más y el dicho Atabalica no venía tuvo miedo de su demora, y envió inmediatamente a donde su hermano Fernando Pizarro a quince hombres a caballo ${ }^{14}$ para comunicarle lo que sucedía, y que le pluguiese venir a verlo de inmediato, cosa que él hizo sin demora. El mismo día Atabalica se puso en camino para venir

- El texto llama Tabalica o Atabalica (quechua Ataw Wallpa) a Atahualpa. Lo común a las crónicas antiguas es la adopción del nombre con $b, l$ y $i$ anaptíftica (Atabalique, Atabalico, Atabaliba, Atabalipa).

10 El texto dice couverte de l'extremité des canes, literalmente *cubierta con la extremidad de las cañas». Quizás haya que entender que las cañas del techo de la casa llegan a cubrir la muralla. P. B. prefiere traducir «cubierta de cañas en sus extremos».

11 En los textos más antiguos, e inclusive en otros más tardfos, el topónimo tiene esta forma, que parece corresponder al fonetismo de la lengua general (la koiné impuesta por los incas) del Tahuantinsuyo ( < kaša «espina», < malka «tierra», que corresponde a marka en otras variedades, forma que predominó en el topónimo moderno Cajamarca, con la / $/$ / evolucionada a / $/$ /).

12 P. B. interpretó têtes (es decir, tentes, con la abreviatura resuelta) como «cabezas» en lugar de «tiendas», y creyó que esto confirmaba «la indole sanguinaria de Atahualpa», que habría adornado el entorno de su casa con las cabezas de sus enemigos.

18 Tal vez, como sugiere P. B., subyazca aquil la palabra quechua apu «señor principal».

14 En la traducción de P. B. Pizarro envia a su hermano Hernando con quince hombres de a caballo a buscar a Atahualpa; pero el texto francés sólo se puede interpretar en el sentido de nuestra traducción. 
a la ciudad de Caxamalca y llegó en la tarde, el cual, estando en su litera muy adornada de oro fino, vino a ver al gobernador y lo cargaban muchos caciques. Había delante de él muchos indios que limpiaban el camino, por más que éste estuviese muy limpio y que no hubiese nada que limpiar. Después había muchos otros, de los cuales unos cantaban y otros danzaban. Alrededor de él había un gran número de indios que ellos llaman gandules ${ }^{15}$, que eran de su guardia: unos llevaban hachas como armas, otros alabardas hechas de plata, y gruesas mazas colgadas de sus cinturas. Había asimismo un gran batallón de estos gandules, en el cual había gran número de gente, todos armados con jabalinas, arcos y flechas; y también de otro costado otro batallón semejante de estos [7] mismos gandules armados igual que los otros. De esta manera entró Atabalica a la ciudad dejando asimismo en los campos un gran número de gentes que eran - según me fue informado - más de cuarenta mil gandules que portaban picas de veinte pies de largo sin contar las hachas, alabardas, mazas y hondas. A su gente que estaba en los campos, según supe luego, les había ordenado que una parte de ellos se emboscara de un lado de la ciudad, y la otra del otro, a fin de que cuando se aproximara a la ciudad si los cristianos querian huir fuesen rodeados por todos los lados, y le parecía que los tenía ya en la mano.

El gobernador, viendo que Atabalica venía a la ciudad, hizo poner a toda su gente en orden, tanto a pie como a caballo y los dividió en dos partes; hecho esto, envió a un padre de la orden de Santo Domingo, el cual se llamaba hermano Vicente, para hablar al dicho Atabalica, el cual padre le habló, y llevaba en sus manos un libro donde estaban los Evangelios y dijo a Atabalica que las cosas que estaban escritas en ese libro era lo que Dios les ordenaba hacer. Entonces Atabalica le dijo que le mostrase el libro, cosa que el padre hizo, y apenas lo tuvo entre sus manos lo arrojó al suelo. El dicho padre lo recogió del suelo y se volteó hacia el gobernador gritando en alta voz y diciendo que había que exaltar la fe de Jesucristo. Al oir esto, el gobernador salió armado con una espada y una rodela en las manos, a

1s Gaudules, como dice el original, no parece ser sino resultado de una confusión de $u$ y $n$, sea del refundidor francés, sea del cajista de Lyon: se trata de gandules windios de guerra, jóvenes y corpulentos», voz que aparece en textos americanos desde 1526 (cf. P. Boyd Bowman, Léxico bispanoamericano del siglo XVI, Londres, 1971; vid. también Georg Friederici, Amerikanistisches Wörterbuch, Hamburg, 1960, s. v.). Es de origen árabe $(<$ gandar) y está documentada desde la segunda mitad del siglo xv para referirse a hombres de guerra entre los moros; aparentemente, se popularizó con motivo de las guerras granadinas y luego pasó a América con un significado análogo, adaptado a la nueva situación. Lo curioso es que no se registra lexicográficamente hasta el diccionario académico de 1869 , y ya con la acepción moderna (según Corominas-Pascual, DECH, s. v.). P. B. conjeturó en Gaudules una palabra quechua deformada por la doble traducción, que habria designado a los orejones; pero la explicación por gandules parece la única verosimil. 
pie, y con él toda la gente que tenía tanto de a pie como de a caballo. Llegando el gobernador donde estaba el dicho Atabalica le [8] puso la mano encima y lo arrojó fuera de donde estaba, y los otros cristianos comenzaron a matar a todos aquellos que lo cargaban y van con gran coraje a pelear dentro del batallón de los indios, donde mataron a gran número de ellos, y duró la batalla desde la tarde hasta que se hizo noche, en que cogieron a varios de los principales de los indios. El botin que obtuvieron está estimado en cuarenta mil castellanos de oro y treinta mil marcos de plata y hubiéramos obtenido más, pero como era de noche los indios que se escapaban se llevaron el resto durante toda la noche. El dicho Atabalica, viéndose prisionero y temiendo ser muerto, prometió a los cristianos darles una casa llena de oro de veinte pies de altura y de dieciocho de ancho, cosa que fue hecha como había prometido, y todo el oro que estaba en esta casa como otro que hizo poner asciende en total a tres millones de castellanos, $y$ asimismo dio tan gran cantidad de plata que no se sabría contar ${ }^{16}$. De la cual suma pertenecen a Vuestra Majestad por vuestro derecho, trescientos mil pesos de buen oro, cada uno de los cuales vale cuatrocientos y cincuenta maravedís, de la cual suma os lleva en este momento Fernando Pizarro ciento cincuenta mil pesos de oro, y cinco mil marcos de plata; no os lleva más porque no hay navíos en que os lo pueda llevar. Es una cosa maravillosa, según se dice, ya que repartiéndose este tesoro le tocó a cada hombre de a caballo como parte diez mil castellanos de oro, y trescientos cincuenta marcos de plata, y a cada hombre de a pie cinco mil castellanos de oro y ciento sesenta y cinco [9] marcos de plata.

Mientras estas cosas pasaban y el gobernador tenía prisionero a Atabalica, mandó decir a Antonio Pizarro ${ }^{17}$ que tomase una cantidad de hombres de a caballo y que fuese a indagar sobre otro gran señor de mayor poder y riqueza de lo que es Atabalica, al cual llaman el Cusco ${ }^{18}$, el cual es hermano del dicho Atabalica y vive en un señorio y país que es el más rico que hay en todo el mundo. Hay en ese pais un templo cuyas paredes son todas de oro y de plata y lo llaman la Casa del Sol, la cual vigila mucha gente de guerra. Dicen que es el país más fértil y placentero que se podría encontrar. Los caminos son muy anchos y limpios y de legua en legua hay pilares, y en cada pilar hay un indio en posta esperando alguna noticia, el cual viendo a alguno se va gritando en alta voz diciendo al otro la causa

16 El sentido exige aqui un punto, por más que en el original no haya ninguna indicación. La traducción de P. B. no es inteligible: «... que no se sabría nombrar que suma pertenece a Vuestra Majestad de vuestro derecho trescientos mil pesos de buen oro ....*.

17 Se trata, sin duda, de una confusión con Hernando Pizarro.

18 El topónimo Cusco se confundió en las primeras crónicas con un antropónimo, referido a Huayna Capac y a Huáscar, padre y hermano de Atahualpa, respectivamente. 
por la que va, y el otro le hace señal de que lo ha oído bien, desciende de donde está subido y va corriendo hasta el otro pilar, y el otro sube al mismo pilar de donde el otro bajó, de manera que los señores de este pais saben lo que quieren en breve tiempo.

Llegando Fernando Pizarro donde el dicho Cusco vivía le fue dicho que estaba muerto a causa de que su hermano Atabalica lo había hecho envenenar. En esta provincia hay muy grandes y caudalosos ríos sobre los cuales hay puentes hechos con cuerdas gruesas y entre una y otra hay cuerdas más delgadas tejidas en forma de una red bien apretada y menuda; y de esos puentes hay dos, por donde pasan los señores, y el otro por donde pasa el común. En todos los caminos [10] de un lado y de otro hay una muralla hecha de adobe. Hay de cada lado del puente gente que vive alli mismo, que no tiene otro oficio ni cargo sino reparar y componer los puentes y apenas una cuerda se gasta o está rota poner otra. Fernando Pizarro cuenta de este viaje noticias tan grandes y maravillosas que es casi imposible convencerse. Mientras estas cosas sucedian, y que el gobernador estaba en la ciudad de Caxamalca, el dicho Atabalica se proponía matar a todos los cristianos, y para hacer esto había apostado cuatro mil gandules, todos gente de guerra, cosa de la cual el gobernador fue advertido por los indios de la ciudad de Caxamalca, el cual sabiendo con certeza que la cosa se habia verificado e incluso por la confesión del dicho Atabalica, fue condenado el dicho Atabalica a ser quemado, el cual Atabalica pidió que se lo hiciera cristiano, y que queria morir como buen cristiano y pidió ser bautizado, cosa que fue hecha, y al estar bautizado encomendó su alma a Dios, y primero lo estrangularon y después lo quemaron. Sucedió luego que tenía otro hermano que era aún joven, el cual vino donde el gobernador rogándole que aceptara darle una carta de ser señor del país de su padre porque era su heredero, y que quería ser súbdito de Vuestra Majestad y servir a los cristianos. El gobernador, habiéndole hecho jurar la fe le otorgó el título de señor del pais y señorío de su padre en nombre de Vuestra Majestad, el cual inmediatamente prometió hacer al gobernador un presente de gran cantidad de oro.

Hechas estas cosas el gobernador partió para ir [11] a Xaxuxa ${ }^{19}$ y Chincha, que son dos grandes ciudades situadas en la mejor región de todo el país y había resuelto hacer una población a veinte leguas del puerto de mar, donde vivirian los cristianos; pero apenas estas ciudades tuvieron noticia de la muerte del dicho Atabalica vinieron ante el gobernador con gran cantidad de oro $\mathrm{y}$ de plata, $\mathrm{y}$ esto para hacerle un presente porque estaban muy contentos de la muerte de Atabalica, porque le deseaban gran mal. El gobernador les agradeció mucho y no lo quiso aceptar, y les dijo

10 Error por Xauxa, antecedente del moderno Jauja. 
que lo llevasen con ellos, porque habia resuelto ir a ver esas dos ciudades y alli lo recibiria, cosa que ellos hicieron. Los caciques que este oro llevaban, entre las piezas que tenian habia cuatro ovejas de oro del tamaño de las ovejas de la tierra ${ }^{20}$, que son del tamaño de un pollino de cinco o seis meses, y con aquellas dos pastores de oro del tamaño de dos hombres pequeños. Item un cántaro ${ }^{21}$ de oro tan bien hecho como era posible, que pesaba diez y ocho mil pesos de oro, en el cual Atabalica solia lavarse. Hay en esta provincia del Perú, en muchos lugares, minas de oro muy ricas, de las cuales han sacado piezas de oro fino que pesan doce y quince libras, y algunas más y algunas menos; este oro es de veinte y veintiún quilates, este oro es tan fino que para hacer con él algunas piezas, y a fin de que sea más fuerte, lo mezclan con plata o cobre. Los hombres están vestidos según su costumbre. Las mujeres están cubiertas hasta los pies y tienen los brazos descubiertos. Dicen que son más blancas que las indias que están en España. Los grandes señores [12] del país llevan puestas bellas camisas bien labradas y por encima mantos que les cubren la cabeza y los amarran por debajo de la barbilla; en lo cual se conocen los grandes señores entre los otros. Los cristianos han tenido ya noticias de otro país que está a doscientas leguas de alli, y dicen los indios que hay aun mayores riquezas de oro y de plata y piedras preciosas que en el país en el que están, y dicen que la gente del lugar es extraordinariamente grande, como gigantes, y son muy valientes en la guerra, y usan cierta hierba que ponen en las flechas cuando disparan, y que los caminos del país son muy bellos y amplios, y que en muchos lugares usan zapatos de oro y de plata, no se sabe con certeza sino por lo que dicen los indios del país.

Memoria de las cosas y piezas tanto de oro como de plata que llevan a España, y yo pienso que es para hacer un regalo a Vuestra Majestad.

Primeramente, veinticuatro vasijas hechas a modo de tinas de España, que contiene cada una siete cubos y medio de agua, y aun más que menos,

20 Cf. la nota 5. Las ovejas de la tierra eran los auquénidos, particularmente las llamas.

21 El texto dice fontaine, palabra que cabe interpretar como «cántarow o en el sentido de «artificio con que se hace correr el agua en los jardines y otras partes de las casas, calles o plazas, para diferentes usos.... (Aut., s.v.). Si lo primero, el texto de base español quizá dirfa cántaro, palabra profusamente documentada en inventarios similares (cf. P. B., pág. 43); si lo segundo el texto diría fuente, uso del cual el siguiente pasaje de F. de Xerez (La Conquista del Perú, Sevilla, 1534, ed. facsimilar, Madrid, El Crotalón, 1983, 15b/16a) da claro testimonio: «Dixo el capitán que aquel indio avia venido con cierto presente para el gobernador. Este mensagero dixo al governador que su seńor Atabaliba le avia enbiado desde Caxamalca para le traer aquel presente que eran dos fortalezas a manera de fuente figuradas en piedra con que bevas. En lo que sigue, donde no parece haber duda de que se trataba de cántaros, usamos esta palabra para fontaine. 
del espesor de medio dedo, y parece que hay gran cantidad de oro en su hechura.

Item trece planchas o tablas de oro, tanto grandes como pequeñas del mismo espesor susodicho, y que usan para adornar sus puertas y algunos bancos.

Item cincuenta fuentes pequeñas ${ }^{22}$ de oro para servir en la mesa.

Item dos fuentes grandes de oro.

Item otra fuente grande de oro.

Item veinticuatro escudillas con asa de oro fino.

Item ocho cargas de oro en dieciséis fardos que pesan sesenta y cuatro quintales, y son pequeñas piezas, y como no hemos querido [13] desatar los fardos no hemos visto las piezas que están adentro.

Item dos grandes sacos hechos de oro a la manera de los sacos de labradores, que contienen cada uno dos medidas ${ }^{23}$ de trigo.

Item otros dos fardos de oro totalmente llenos de pequeñas piezas que pesan ocho quintales.

Item otras dieciocho planchas de oro, tanto pequeñas como grandes.

Item una mujer hecha de oro y plata.

Item dos pequeñas cajas de oro.

Item dos grandes caracoles de oro.

Item veinte capones de oro, tanto grandes como pequeños, que pesan cada uno cien pesos.

Item un escritorio con su pluma, todo de oro.

Item tres pequeños recipientes de oro.

Item tres tapas de oro de esas vasijas que llaman tinas de oro.

Item otras seis fuentes grandes de oro.

Item dos tapas de tupines, de oro.

Item otra pequeña caja de oro.

Item cuatro anteojos de oro.

Item otras tres tapas de tinas, de oro.

Item dos cántaros de oro.

Item dos medallas de oro donde está el retrato del Cusco y de su mujer, todo puesto en una caja de plata.

Item un hombre de oro de la altura de un nifio de diez años.

Item dos cañas ${ }^{24}$ de maiz y hay en cada una dos mazorcas de oro.

23 Traducimos uniformemente plat (el texto distingue pequeños, medianos y grandes) por fuente.

23 Bibet en el original; probablemente por bichet, nombre de una antigua medida de capacidad de granos.

24 El texto francés trae lictz, probablemente resultado de una mala lectura del texto de base, que dirfa cannas (quizá con abreviatura), interpretado como camas. P. B. acertó en la traducción «espigas", aunque sin indicar la fuente del error. 
Item dos carcajes de oro para llevar saetas y flechas.

Item un espejo de oro.

Item otras tres fuentes de oro.

Item dos atabales de oro de los que usan en la guerra como nosotros

los tamborines de Suiza, que pesan ciento veinte marcos de oro.

Item dos capones de oro esmaltados.

Item dos grandes tupines de oro.

Item una pequeña caja de oro.

Item un pequeño recipiente de oro.

Item dos grandes botellas de oro.

Item dos castillos medianos de oro.

Item otros cántaros de oro [14].

Item una cuchara de oro.

Item un jarro de vino de oro.

Item otro recipiente de oro.

Item XXII camisas labradas con oro y plata, y con plumas a la moda del país.

Item XXVII mantos del más extraño tipo que sea posible ver.

Item llevan cuarenta y ocho vasijas de plata que llaman tinas, conteniendo cada una siete cubos y medio, del ancho de un dedo, de manera que un mulo estaría bien cargado llevando dos de estas vasijas.

Item cincuenta fuentes pequeñas de plata para servir en la mesa.

Item dos fuentes medianas de plata.

Item una fuente grande de plata.

Item XXIIII fuentes pequeñas de plata.

Item un jarro de plata hecho a la moda del país.

Item un soporte de plata sobre el que se ponen las fuentes sobre la mesa.

Item dos cántaros de plata.

Item dos tupines de plata.

Item otras dos fuentes de plata esmaltadas.

Item dos capones esmaltados de plata.

Item otra fuente de plata.

Señor, se van veintidós o veintitrés hombres que han estado en esta guerra, de los cuales algunos llevan veinte mil pesos de oro, algunos dieciocho, algunos dieciséis, y el que menos lleva es diez mil pesos. Fernando Pizarro, en cuanto a lo que hemos visto, lleva más de LXXX mil pesos de oro, sin contar lo que lleva secretamente.

Señor, me parece lícito y conveniente que sepáis cuánto valoran y estiman el oro aquellos que están en la provincia llamada el Perú. Debéis saber que había dos compañeros y uno de ellos pidió prestados dos mil cas- 
tellanos al otro, cosa que el otro hizo. Aquel que los había pedido prestados, habiendo hecho lo que [15] tenía que hacer, quiso devolverlos al otro en buen oro. Aquel que los había prestado le dijo al otro que los guardase todavía, ya que por el momento no podía recibirlos. Aquel que los había pedido prestados lo requirió ante testigos muchas veces que los recibiese, cosa que el otro jamás quiso. Entonces se fue ante la justicia y le hizo requerir que tomase su dinero, el cual respondió rogando al juez que aceptara no hacérselos tomar, porque dado que no sabía dónde poner lo que tenía, cómo podría recibir esos dos mil ducados, y que hiciese lo posible ante quien los tenía que los guardase y que él no se los pediría jamás. Debatieron tanto entre ellos dos, uno defendiéndose de tomarlos, el otro queriendo a toda costa devolverlos, hasta que llegaron a un acuerdo por medio de sus amigos, que como los dos iban a la ciudad de Caxamalca, que aquel que tenía el oro del otro que lo llevase hasta Caxamalca, y que llegando a la ciudad aquel que los había pedido prestados devolviese mil castellanos al otro y que retuviese los otros mil por el trabajo que había tenido al traerlos. Cosa que fue hecha tan liberalmente, que incluso a aquel que los había prestado le parecía que el otro lo forzaba haciéndole recibir esos mil castellanos de los dos mil. Os pongo por juez de si alguien habría litigado y se habría hecho de rogar por una cosa así en Castilla.

\section{F I N}

